\title{
Exploring parental experiences of virtual paediatric neurodevelopmental consultations
}

\author{
Rebecca Finnegan $^{1}$ [D $\cdot$ Aoife Flynn ${ }^{1} \cdot$ Orla Flanagan $^{1}$
}

Received: 10 February 2021 / Accepted: 26 February 2021 / Published online: 23 March 2021

(c) Royal Academy of Medicine in Ireland 2021

\begin{abstract}
Objective The coronavirus pandemic resulted in dramatic changes and challenges to healthcare practices. We endeavoured to establish the experiences of families of children attending a neurodevelopmental service after a transition to virtual consultations.

Methods Anonymous questionnaires were posted to parents of children registered in virtual clinics over a 10-week period. Results Thirty parental questionnaires were completed. Parents reported a very high level of satisfaction (8.2/10) with previous face-to-face clinic appointments and virtual consultations (8.2/10). Individual aspects of virtual consultations received very positive ratings. Overall, $77 \%$ of parents highlighted a future preference for a combined service of both virtual and face-to-face consultations.

Conclusions This study highlights the high level of parental satisfaction with the service, but especially satisfaction with the unplanned transition to virtual clinics. Virtual clinics cannot replace the holistic approach gained from face-to-face consultations; however, we identified their benefits of convenience and accessibility for our vulnerable population. In response, we have developed an integrated outpatient service involving both forms of consultation to potentiate satisfaction and adapt to meet the needs of our patients. The suggested proforma that has been developed offers a simple structure for undertaking a virtual consultation that can be adapted to different specialities, integrating the suggestions provided by our service users.
\end{abstract}

Keywords Child health · Covid-19 $\cdot$ Developmental disabilities $\cdot$ Patient satisfaction $\cdot$ Telemedicine

\section{Dear Editor,}

The coronavirus pandemic (COVID 19), which emerged in Ireland in early 2020, resulted in dramatic changes in both society and healthcare practices. Paediatrics, like other healthcare services, had to quickly adapt to providing outpatient care by virtual means in order to reduce patient contact [1]. Children attending a neurodevelopmental service often have very complex medical conditions and additional care needs. A simple visit to an outpatient clinic is not without its difficulties and stress for the child and their family.

While it has previously been reported that there are high levels of patient satisfaction with telehealth [2,3], there is limited research exploring parent and patient satisfaction among paediatric cohorts, in particular children with complex

Rebecca Finnegan

Rebeccafinnegan2@icloud.com

1 Department of Paediatrics, Galway University Hospital, Galway, Ireland care needs. While healthcare professionals in our service identified the benefits of virtual clinics, we endeavoured to establish whether the parents of the children attending our service also shared this viewpoint. Anonymous questionnaires were sent to parents of children who were scheduled for a review appointment in the form of a virtual consultation in the neurodevelopmental service over a 10-week period.

Thirty anonymous questionnaires were completed and returned. Parents reported a very high level of satisfaction (8.2/10) with both previous face-to-face clinic appointments and virtual consultations (8.2/10), illustrated in Fig. 1. Considering some individual aspects of virtual consultations, 97\% felt they received adequate time during the consultation and $90 \%$ felt they were contacted at an appropriate time of day. Similarly, $86 \%$ of respondents felt their concerns were managed well and received adequate and correct information when sought.

Feedback received from parents regarding their experience of the telephone consultation varied. Some were very happy with the service they received, commenting 'really 


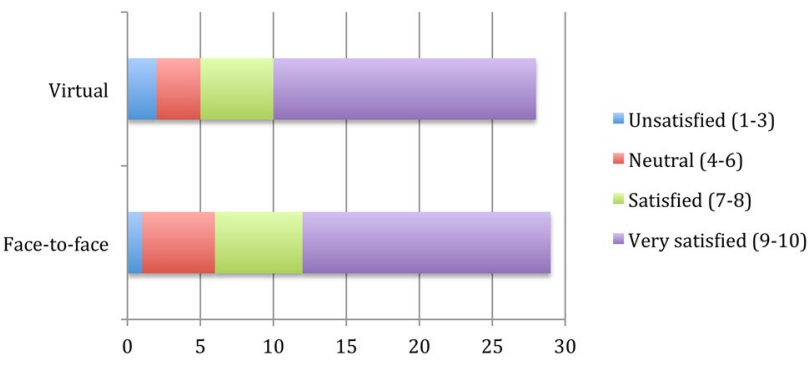

Fig. 1 Satisfaction scales - virtual and face-to-face

went the extra mile with the help' and 'great initiative', while a minority of respondents found the experience to be disappointing, reporting 'very rushed, barely any questions asked' and 'the person calling should do a background check of the patient and not make assumptions'. Seventy-seven per cent of parents were happy with a combination service of both virtual and face-to-face appointments in the future.

These results demonstrate the high levels of parental satisfaction with both traditional face-to-face clinics as well as the newly developed virtual consultations in our service. This finding replicates previous published literature comparing the two formats of consultations in adult services [4]. It is clear that virtual consultations, if undertaken in the correct manner, are a very adaptable measure to future service provision. Despite this being the first time that virtual consultations were implemented in our service, it was delightful to see the high levels of feedback and response to this new service.

In order to optimise on the service provided through virtual consultations and implement the feedback from parents, we have developed a clear structured proforma for use in our service when undertaking virtual consultations, outlined in Fig. 2. This proforma can be incorporated to not only standardise the consultation, but it also provides a template for less experienced staff to ensure all areas of the consultations is covered.

In conclusion, this study demonstrates the suitability and satisfaction of virtual consultations as an alternative to faceto-face clinic appointments. However, one must remember that virtual consultations cannot build the same rapport and connection with patients that are gained from face-to-face meetings, and should not be used as a complete substitute for the other [4]. Therefore, we identified their benefit and role in developing an integrated service involving both forms of

\begin{tabular}{|c|c|c|c|}
\hline Patient Details & & & \\
\hline Medical Background & & & \\
\hline When was last clinic visit & & & \\
\hline Issues at last visit & & & \\
\hline Main concerns at present & & & \\
\hline Current medications & & & \\
\hline Sleep & & & \\
\hline Diet/Weight & & & \\
\hline Bowels & & & \\
\hline Seizures (if appropriate) & & & \\
\hline Developmental Gains & & & \\
\hline Recent GP/hospital visits & & & \\
\hline Community Services & & & \\
\hline Follow up preference & F-F & $\square \quad$ Virtual & 口 \\
\hline Script needed & Yes & $\square \quad$ No & $\square$ \\
\hline Information requested & Yes & No & $\square$ \\
\hline Any other questions & Yes & $\square$ & $\square$ \\
\hline Urgent F-F required after call & Yes & $\square$ & $\square$ \\
\hline Next appointment date: & & & \\
\hline Name of team member & & & \\
\hline Grade of team member & & & \\
\hline
\end{tabular}

Fig. 2 Virtual consultation proforma (condensed)

consultation. This study highlights the high level of parental satisfaction with the service, and offers reassurance to healthcare professionals that appropriate and satisfactory care and support can be provided through virtual means if necessary. The suggested proforma offers a simple structure for undertaking a virtual consultation that can be adapted to different specialities, integrating the suggestions provided by our service users.

\section{References}

1. Monaghesh E, Hajizadeh A (2020) The role of telehealth during COVID-19 outbreak: a systematic review based on current evidence. BMC Public Health 20(1):1-9. https://doi.org/10.1186/ s12889-020-09301-4

2. Mair F, Whitten P (1996) Systematic review of studies of patient satisfaction with telemedicine. Br Med J 313(7055):438. https:// doi.org/10.1136/bmj.313.7055.438

3. Healy P, McCrone L, Tully R et al (2019) Virtual outpatient clinic as an alternative to an actual clinic visit after surgical discharge: a randomised controlled trial. BMJ Qual Saf 28(1):24-31. https:// doi.org/10.1136/bmjqs-2018-008171

4. McKinstry B, Hammersley V, Burton C et al (2010) The quality, safety and content of telephone and face-to-face consultations: a comparative study. Qual Saf Heal Care 19(4):298-303. https:// doi.org/10.1136/qshc.2008.027763 